\title{
Performance tests of a PI speed controller applied in a non-linear model of a switched reluctance motor $8 / 6$
}

\author{
J. D. GONZÁLEZ-SAN ROMÁN, J. U. LICEAGA-CASTRO, I. I. SILLER-ALCALÁ AND E. \\ CAMPERO-LITTLEWOOD \\ Department of Electronic \\ Universidad Autónoma Metropolitana-Azcapotzalco \\ Av. San Pablo Xalpa 180, Reynosa Tamaulipas, Azcapotzalco, C.P. 02200 Ciudad de México
}

MÉXICO

\begin{abstract}
This article presents the performance tests, by simulation, of a classic PI speed controller applied to a switched reluctance motor (SRM) 8/6. The motor is represented by a linearization of the simplified non-linear model at an operating point set at 2000rpm. The model includes Coulomb plus viscous friction nonlinearity and an ideal inverter circuit. The control system simulations that are carried out are divided into two types: regulation tests and tracking tests, all simulations are carried out in Matlab ${ }^{\circledR}$ / Simulink software.
\end{abstract}

Key-Words: - Switched reluctance motor (SRM), speed control, PI controller, Linear control, Simplified model, Coulomb friction.

Received: March 9, 2021. Revised: August 19, 2021. Accepted: September 9, 2021. Published: September 21, 2021.

\section{Introduction}

The switched reluctance motor is a direct current double salient electric machine that lacks permanent magnets, brushes and rotor windings, its structure has salient poles in both the stator and rotor and concentrated stator windings located in diametrically opposite pairs. Unlike what happens in de motors, in these motors the rotation occurs thanks to the magnetic field that appears when each phase of the stator is energized. The field tends to flow through the rotor poles causing it to adopt the position of minimum reluctance and consequently the field is maximum.

SRM has several advantages such as, simple and robust construction, high torque at low speeds, large power-to-size ratio, efficient energy conversion, wide operating speed range, and easy cooling [1] [4]. For this reason, it has been used in different applications such as washing machines, electric vehicles, electric doors, compressors, vacuum cleaners, air conditioning, pumping, etc. [4] and [5]. However, the SRM also has some disadvantages that can limit its use, such as a large number of connections, audible noise in its operation, requires position sensors and drive circuit and curl in speed and torque signals [6].

To properly take advantage of these characteristics of the SRM, an optimal excitation and control of the same is necessary. This is not easy to obtain experimentally and it can even be a difficult and time-consuming task, depending on the complexity of the controllers, to implement the necessary tests. For this reason, computational simulation of proper SRM models and its control systems becomes essential for the analysis and design of controllers for any SRM.

In recent years, various control systems have been made for SRM for different purposes and implementing different control techniques. Some researches base their control systems on the technique of direct instantaneous torque control (DITC) [7] and [8], for example, in [8] where a DITC is proposed that replaces the torque hysteresis with a width modulation pulse control (PWM) to set the switching frequency, reducing torque oscillations. In other works, it is chosen to apply the vector control technique [9] and [10], in the latter this control technique is applied to drive an SRM in the highspeed region with the specifications of low vibration level, high motor efficiency and wide speed range. A commonly used control technique for SRM control is Fuzzy Logic Control (FLC) as implemented in [11] and [12]. In the work developed in [12] an FLC is implemented that determines the gains of a conventional proportional-integral controller executed by a programmable logic controller, the result is a speed control that eliminates overshoots and reduces settling times compared to a conventional proportional-integral controller.

In this work, a classic proportional-integral (PI) controller is proposed that guarantees stability and performance to parametric variations, for the speed 
control of an SRM around an operating point established at $2000 \mathrm{rpm}$. This article follows up on the SRM models comparison work presented in [13]. The ideal inverter circuit that implements the simulation allows the motor to rotate clockwise with positive voltages and with negative voltages the motor to rotate counterclockwise. This allows implementing a speed control through the input voltage variable, avoiding internal current control loops that are very common in the control of SRM's.

\section{Mathematical Model of the SRM}

There are different models to represent the dynamics of the SRM, among which is the so-called simplified model, which considers the following [14]:

- There is no saturation of the material, therefore the flux linkages are described by the product of inductance and phase current.

- The fringing effects are neglected.

- Mutual inductance is negligible.

- The motor phases are identical in resistance and inductance.

- Inductance is a function of rotor position [15].

The equations that make up this model are (1) and (2), which represent the equations that govern the dynamics of the electrical subsystem and mechanical subsystem, respectively.

$$
\frac{d i_{j}}{d t}=\frac{v_{j}-R i_{j}-L_{1} N_{r} i_{j} \omega \sin \left(N_{r} \theta-(j-1) 2 \pi / N\right)}{L_{0}-L_{1} \cos \left(N_{r} \theta-(j-1) 2 \pi / N\right)}
$$

$$
\frac{d \omega}{d t}=\frac{1}{J}\left[\frac{N_{r} L_{1}}{2} \sum_{j=1}^{N} i_{j}^{2} \sin \left(N_{r} \theta-(j-1) \frac{2 \pi}{N}\right)-\tau_{l}-\tau_{f}\right]
$$

Where, $v_{j}, i_{j}$, and $R$, are the voltage, current, and resistance of phase $j, L_{0}$ is the self-inductance of each phase, $L_{1}$ is the inductance dependent on the position of the rotor, $N_{r}$ is the number of poles of the rotor, $N$ is the number of phases of the stator, $\mathrm{q}$ is the rotor position, $\omega$ is the angular velocity, $J$ is the moment of inertia, $\tau_{e}, \tau_{l}$ and $\tau_{f}$ are the corresponding electromagnetic, load and friction torque, the latter is represented by Coulomb plus viscous friction model [16], equation (3).

$$
\tau_{f}=D \omega+\Delta \operatorname{sgn}(\omega)
$$

Where, $D$ is the viscous coefficient and $\Delta$ is the Coulomb friction force. Considering the parameters of the SRM RA130135 from System Tech, with eight poles in the stator, six poles in the rotor $(8 / 6)$ and four phases, given by:

- $V \max =24 \mathrm{Vdc}$

- $N=4$

- $N_{r}=6$

- $J=3.9063 \mathrm{Kg} \mathrm{m}^{2}$

- $\tau_{l}=0.01 \mathrm{~N} \mathrm{~m}$

- $D=0.0001 \mathrm{~N} \mathrm{~m} / \mathrm{rad} / \mathrm{s}$

- $\Delta=0.005 \mathrm{~N} \mathrm{~m}$

- $R=1 \Omega$

- $L_{0}=2.1 \mathrm{mH}$

- $L_{1}=1.3 \mathrm{mH}$

- $\Theta=2^{\circ}$.

The single-phase transfer function of a SRM, that relating rotor's speed to input voltage, is obtained and shown in (4).

$$
\begin{gathered}
G(s)=\frac{\omega(s)}{V(s)}=\frac{283470}{s^{2}+1619.7 s+6740.2} ; \\
\text { poles }=\{-4.2,-1615.5\} ;
\end{gathered}
$$

As can be seen from (4) the transfer function has two extremely separated poles, thus, can be simplified by dominant pole [17], the resulting function is shown in (5).

$$
G(s)=\frac{176.64}{s+4.2}
$$

\section{Proposed PI Controller}

As mentioned above, the classic controller that we want to add to the SRM will be cheap and easy to implement, it also has the task of controlling the motor's speed satisfying the following design specifications; bandwidth around to $8 \mathrm{rad} / \mathrm{s}$, infinite gain margin and phase margin $>60^{\circ}$. The proposed controller was designed using the Bode shaping [18][19] technique, in this way it is possible to gradually adjust both the gain margin and the phase margin by adding poles or zeros and varying its gain and location frequency, up to obtain a Bode plot that reflects the desired margins. The transfer function of the proposed PI controller is shown in (6) 


$$
C(s)=\frac{0.0474(s+4)}{s}
$$

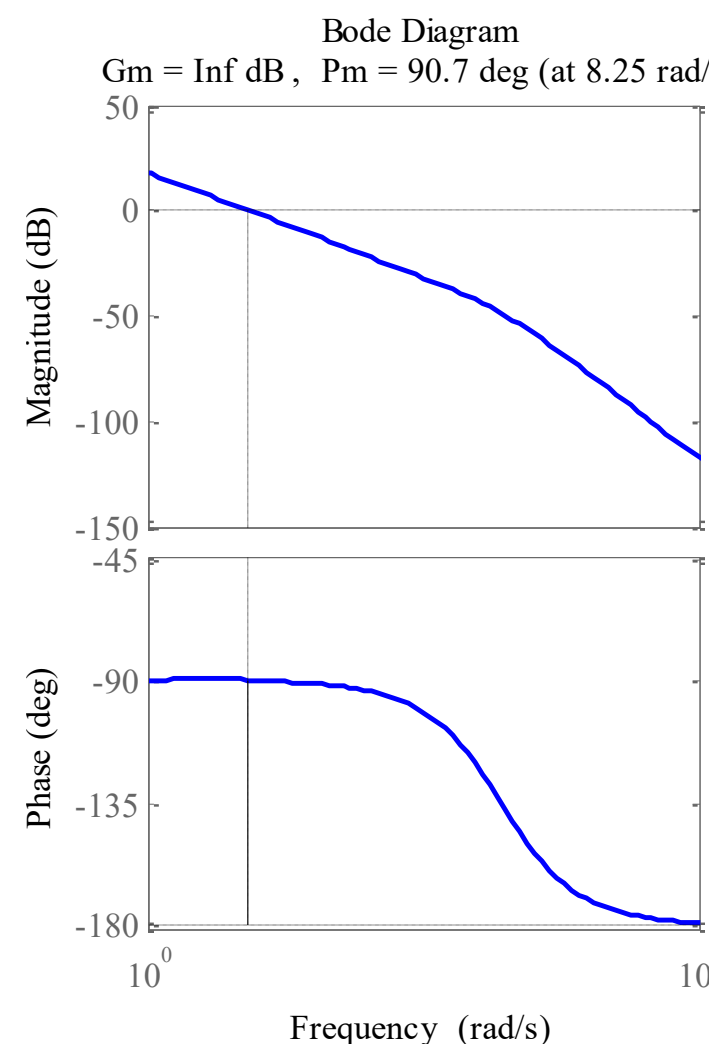

Fig. 1. Control system Bode diagram.

Bode shaping is performed by analyzing the closed loop of the $\mathrm{C}(\mathrm{s}) \mathrm{G}(\mathrm{s})$ system by drawing the Bode diagram of magnitude and phase, Fig. 1. In this diagram it can be easily observed how the controlled system satisfies the design specifications, obtaining an infinite gain margin, a phase margin of $90.7^{\circ}$ and a bandwidth of $8.25 \mathrm{rad} / \mathrm{s}$.

\section{Simulations}

The linear model of the motor that was simulated was programmed in Matlab / Simulink and whose ideal inverter circuit has: Bridge converter topology, demagnetization of the phases, hysteresis current regulation technique, soft chopping technique and the negative voltages are interpreted as counter clockwise turns.

To test the performance of the PI controller, three tests were carried out to evaluate the behavior of the control system in regulation and tracking problems over a wide operating range.

\subsection{Regulation test}

As a first test, a square reference signal is applied from 1500 to $2500 \mathrm{rpm}$ for 15 seconds. In the Fig. 2 to 5 rotor's speed, control input, electromagnetic torque, and current responses for each phase are shown.

From the Fig. 2 It is observed how the control system manages to establish the response of the rotor's speed to the reference signal value with an establishment time of 1 second, the speed response reaches a maximum curl amplitude of $1.1 \mathrm{rpm}$, which corresponds at a curl of $0.07 \%$.

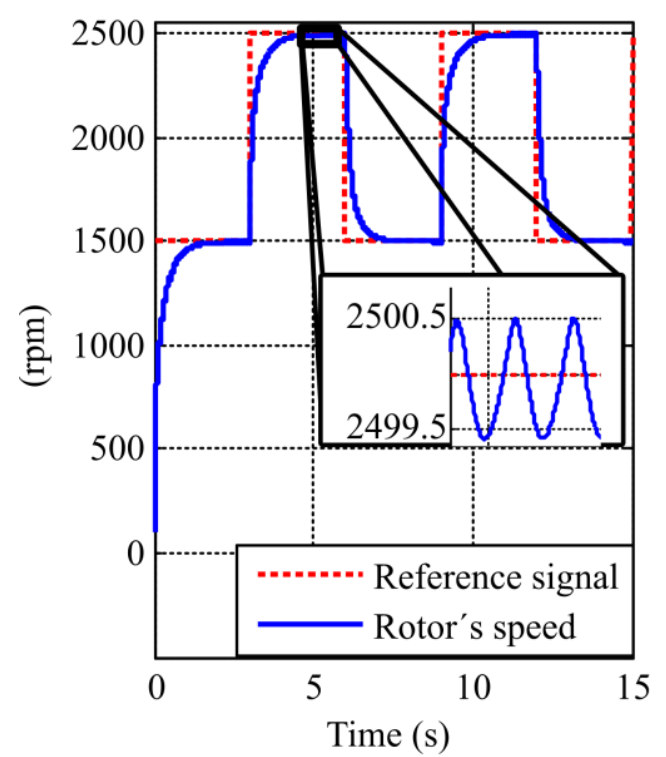

Fig. 2. Rotor's speed response to reference signal from 1500 to 2500 rpm.

From the control input response of the Fig. 3, It is observed how the voltage obtains minimum and maximum values of 4.7 and $10.7 \mathrm{~V}$ respectively, which are reached when the reference signal changes abruptly between 1500 and 2500rpm.

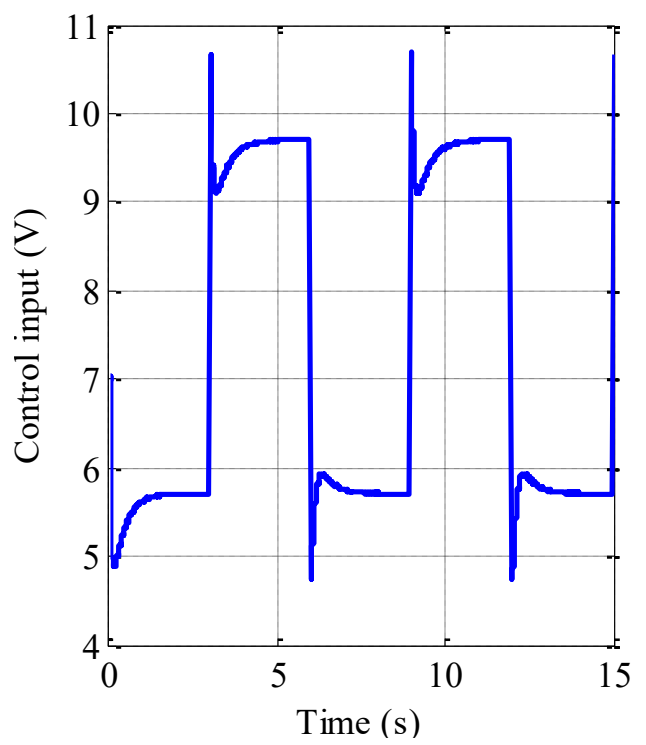

Fig. 3. Control input response to reference signal from 1500 to 2500 rpm.

Regarding the torque response observed in the Fig. 4 It is noted how at the beginning of the test when 
the control signal changes abruptly, this change produces a maximum peak of torque that reaches $0.189 \mathrm{Nm}$ and later, maximum peaks of $0.1 \mathrm{Nm}$ and minimum of $0.004 \mathrm{Nm}$.

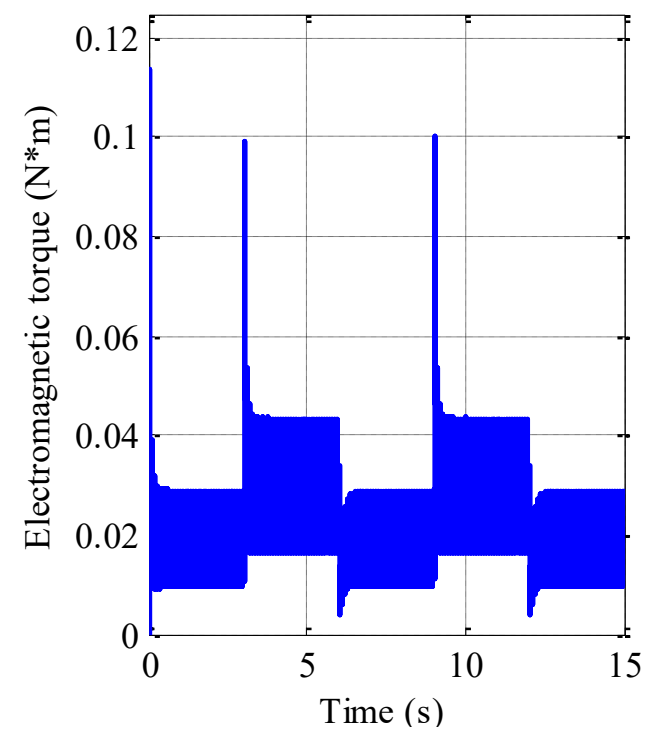

Fig. 4. Torque response to reference signal from 1500 to $2500 \mathrm{rpm}$.

From the Fig. 5 the current responses of each phase are observed, which are very similar to each other. It is important to highlight how even in the instants in which the control input changes abruptly, the maximum current values only reach $5 \mathrm{~A}$.
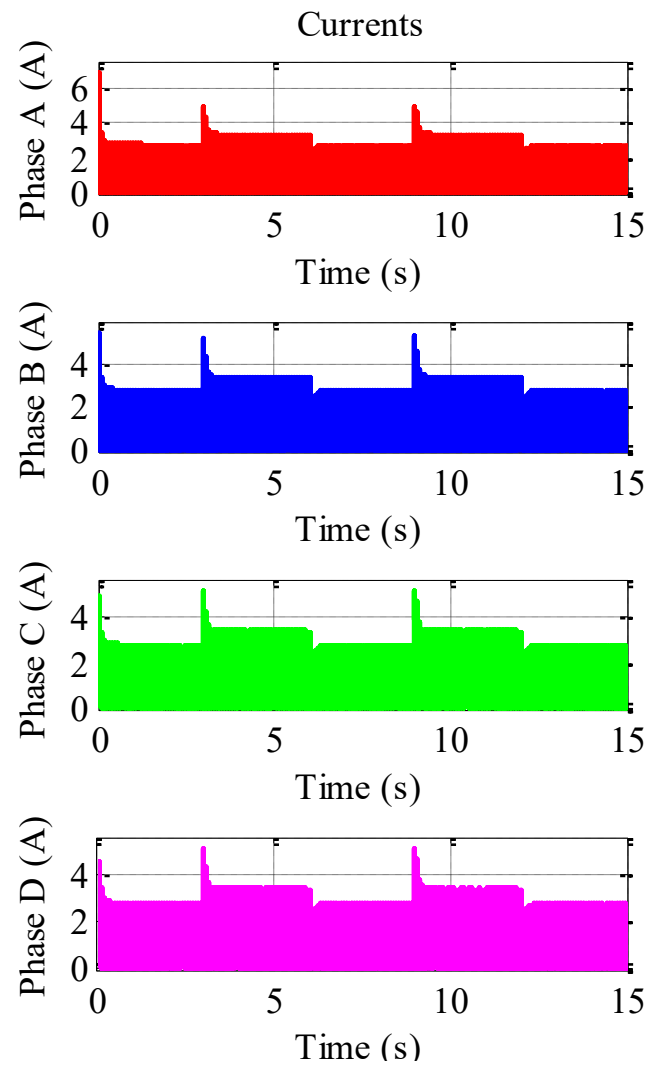

Fig. 5. Phase currents responses to reference signal from 1500 to 2500 rpm.
As a second test, a square reference signal is applied that causes clockwise and anti-clockwise turns at $2000 \mathrm{rpm}$, that is, varying the operating speed from -2000 to $2000 \mathrm{rpm}$. As in the previous test, the responses of speed, control input, electromagnetic torque and current of each phase are observed, shown in the Fig. 6 to Fig. 9.

From Fig. 6 it is observed how the rotor speed reaches the final values of the reference signal even when the reference is at $-2000 \mathrm{rpm}$, like the previous test, the establishment time is 1 second, in this case the curl amplitude reached a maximum value of 1.2 $\mathrm{rpm}$, that is, $0.06 \%$ of curl. This result is expected given that, despite operating in a much wider range, the lower and upper limits are closer to the operating point at $2000 \mathrm{rpm}$ established for this system, and in the case where the reference signal is at $-2000 \mathrm{rpm}$, the behavior of the system is extremely similar to when it is at $2000 \mathrm{rpm}$, thus curls of similar amplitude are obtained.

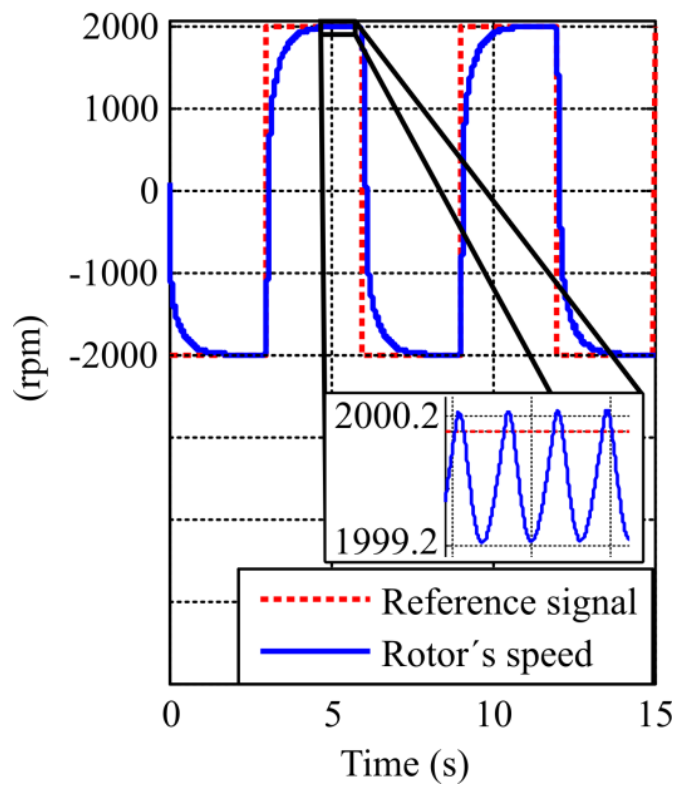

Fig. 6. Rotor's speed response to reference signal from -2000 to 2000 rpm.

In Fig. 7 the response of the control input is observed, which obtains minimum peaks of $-12.28 \mathrm{~V}$ and maximum of $12.11 \mathrm{~V}$, achieving an almost symmetric signal with respect to the time axis, once again this is due to the fact that the clockwise and counter clockwise system behavior are quite similar.

Fig. 8 shows the response of the electromagnetic torque of the motor, it can be seen how in this test the maximum and minimum values reached by the torque are $0.1816 \mathrm{Nm}$ and $-0.1825 \mathrm{Nm}$, which indicates that as with the input control, the torque response becomes practically symmetrical respect to the time axis. It is important to note that despite observing negative quantities in Fig. 8, these are due 
to the fact that the torque is measured with respect to a reference frame.

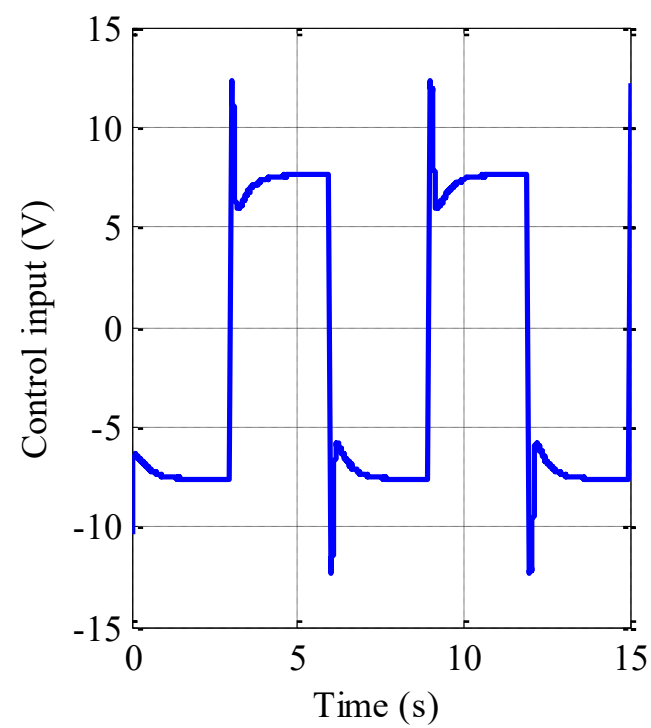

Fig. 7. Control input response to reference signal from -2000 to 2000 rpm.

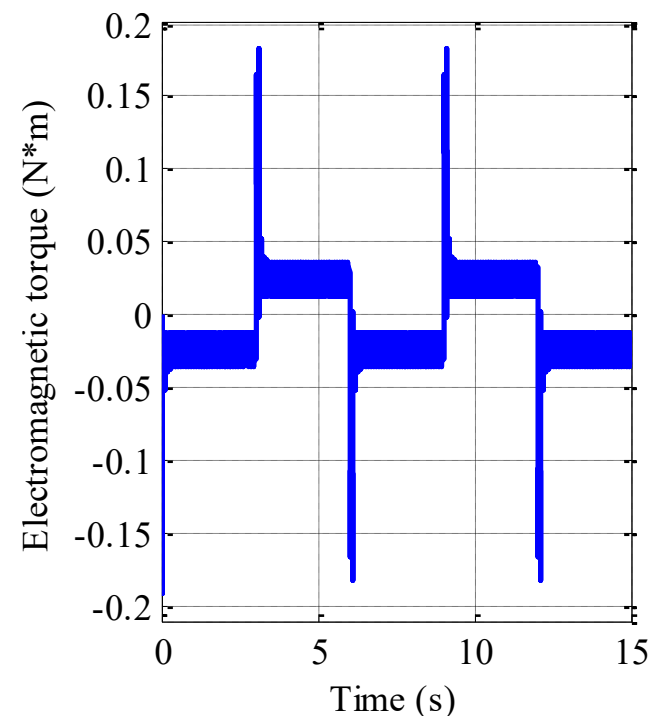

Fig. 8. Torque response to reference signal from -2000 to $2000 \mathrm{rpm}$.

Finally, from the phase current responses shown in Fig. 9, it is observed how all phases reach a maximum current value of $7 \mathrm{~A}$, due to the current regulation of the inverter circuit that the SRM model has. Without this feature, the phase current could have increased to $8 \mathrm{~A}$ or more, which, depending on the resistance of the motor windings, could damage them. It is for this reason that even if the SRM has a position, speed or torque control system, it is necessary to have protection against harmful current increases, which in this case regulates the current through hysteresis.

To conclude the regulation tests, the previous experiment is repeated, but with a reference signal of -500 to $500 \mathrm{rpm}$, in order to observe the behavior of the controller at low speeds. Motor responses are shown in Figs 10 to 13.
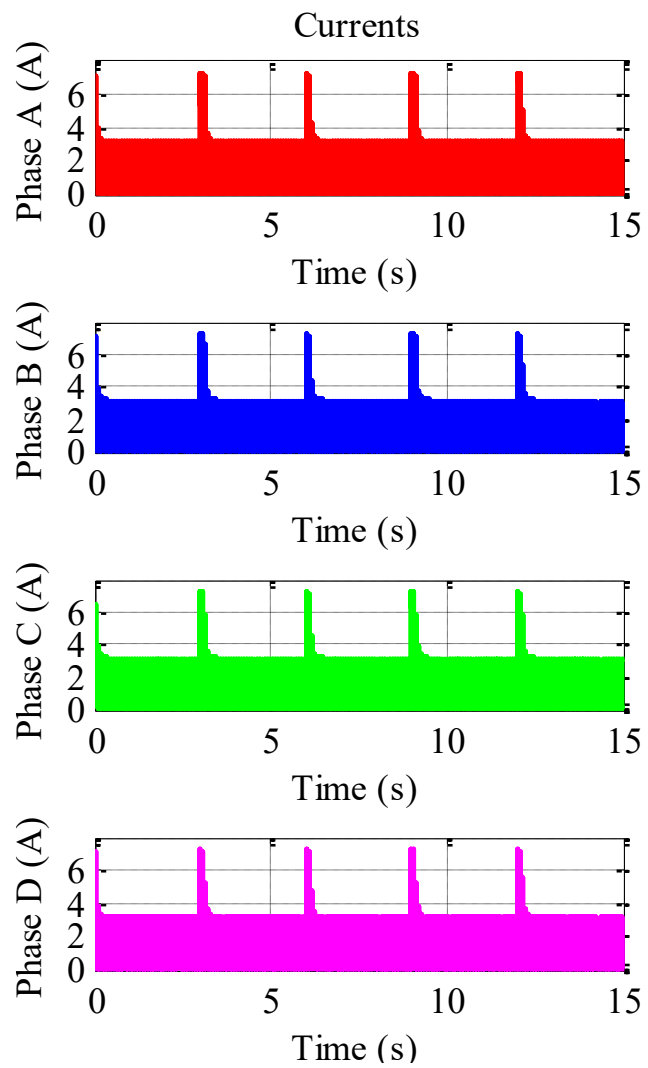

Fig. 9. Phase currents responses to reference signal from -2000 to 2000 rpm.

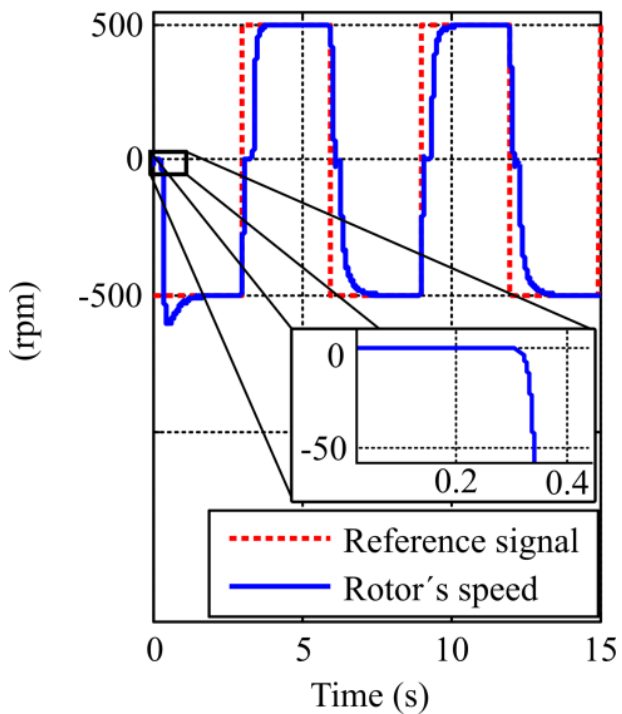

Fig. 10. Rotor's speed response to reference signal from -500 to $500 \mathrm{rpm}$.

In Fig. 10 It is observed how the motor reaches the reference speed obtaining a curl greater than that seen in the previous tests with a value of $0.42 \%$. However, the most remarkable thing about this test is the dead zone that the motor exhibits every time there is a sudden change of rotation. The dead zone occurs due to the friction of the motor, which prevents the rotor from turning with low voltages, this occurs when 
operating the motor at low speeds due to the low voltage demand. In the speed response we can see how the dead zone keeps the rotor without movement for approximately 0.3 seconds, this can cause poor motor performance in some applications that require operating the motor at low speeds. The dead zone problem can be reduced by using a proportional controller with double integral effect (PII), as demonstrated in the work done in [20].

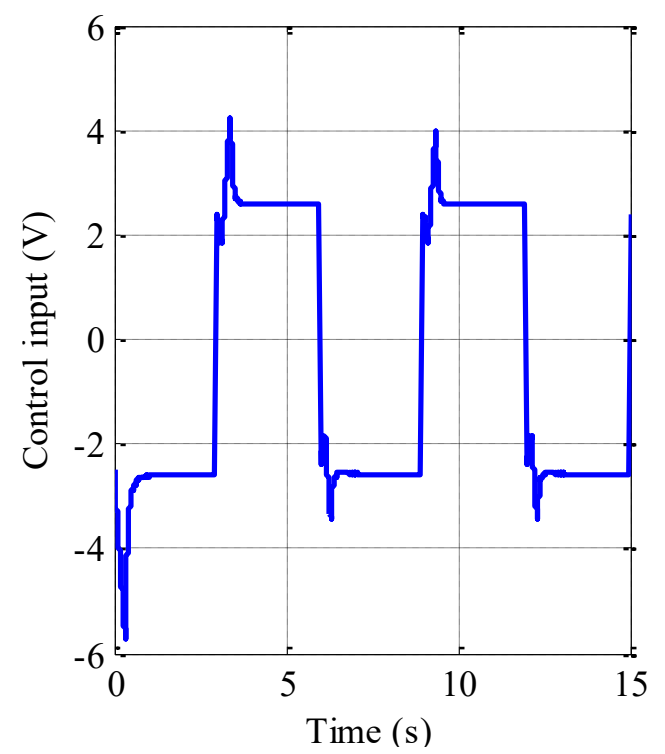

Fig. 11 Control input response to reference signal from -500 to $500 \mathrm{rpm}$.

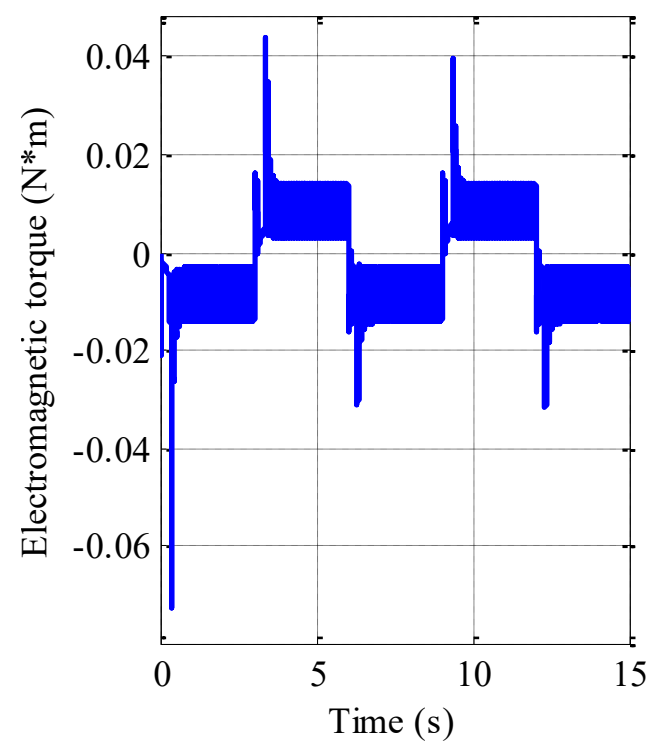

Fig. 12. Torque response to reference signal from -500 to $500 \mathrm{rpm}$.

From Fig. 11 It is observed how the response of the control input is established in symmetric voltages of approximately $2.57 \mathrm{~V}$, presenting voltage peaks in the changes of rotation. As expected, the largest peak is observed at the beginning of the simulation, because the rotor is at rest and, therefore, requires a higher torque to start moving and a higher voltage, compared to what occurs when the rotor is at rest. rotor is already in motion. A similar behavior is observed in the torque response shown in Fig. 12 Where the torque has a maximum peak at the beginning of the simulation.

Finally, in Fig.13 the current responses of the phases, it is observed that the steady state current has low consumption with an average value of $1 \mathrm{~A}$. In a similar way to the control input in the changes of rotation, it is observed how the current increases from gradually, only phase A, this is only due to the fact that the change of rotation occurred when the phase was active.
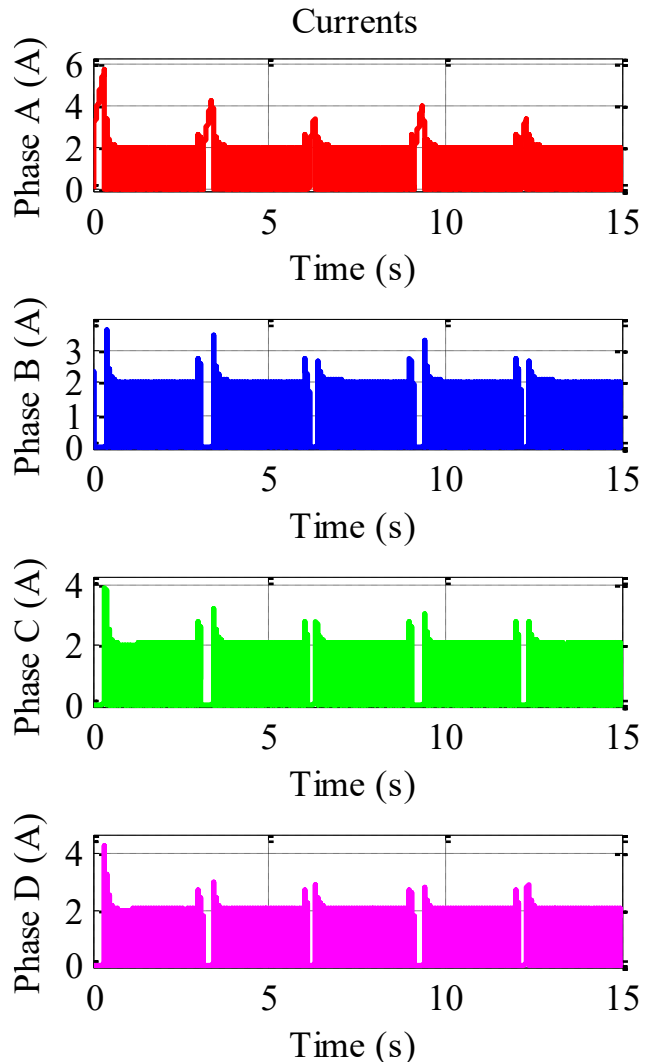

Fig. 13. Phase currents responses to reference signal from -500 to 500 rpm.

\subsection{Tracking test}

For this test, a sinusoidal reference signal is applied to the system that varies between 1000 and $3000 \mathrm{rpm}$ at a frequency of $0.5 \mathrm{rad} / \mathrm{s}$, this oscillation frequency is coherent with the bandwidth of the system, which was obtained is $8.25 \mathrm{rad} / \mathrm{s}$. Fig. 14 to Fig. 17 show the corresponding responses for speed, control input, torque, and phase currents.

In the Fig. 14 is possible to observe how the SRM is able to satisfactorily follow the reference signal with negligible lag, with a maximum error of $0.6 \%$ in the peaks of the reference signal oscillations. The maximum amplitude of the curl obtained is $1.7 \mathrm{rpm}$, which corresponds to a curl of $0.06 \%$. 


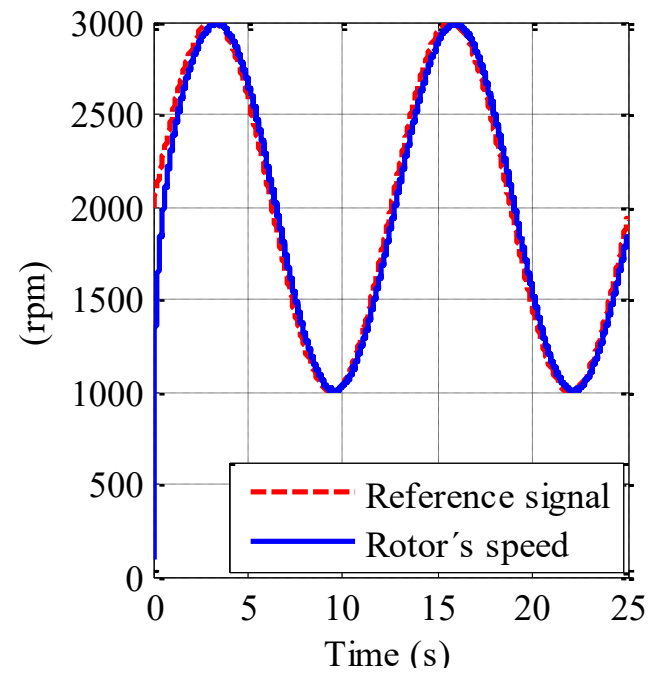

Fig. 14. Rotor's speed response to sinusoidal reference signal from 1000 to $3000 \mathrm{rpm}$ at $0.5 \mathrm{rad} / \mathrm{s}$.

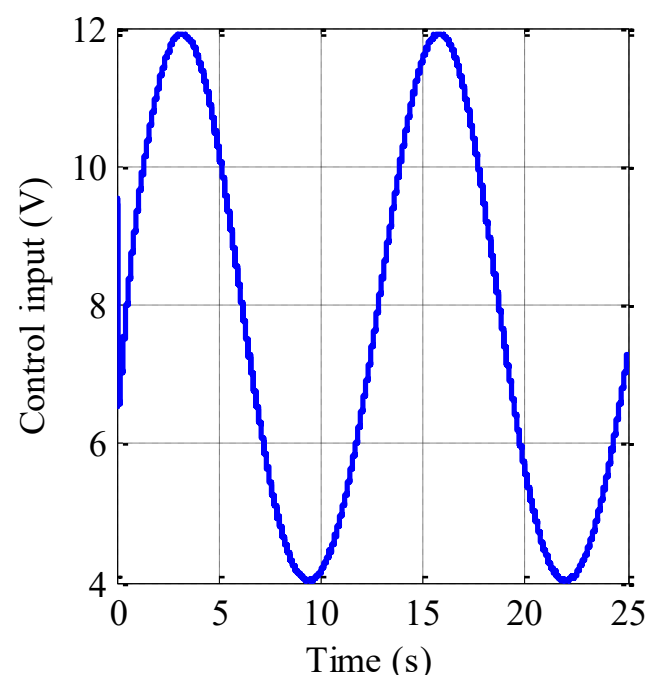

Fig. 15. Control input response to sinusoidal reference signal from 1000 to $3000 \mathrm{rpm}$ at $0.5 \mathrm{rad} / \mathrm{s}$.

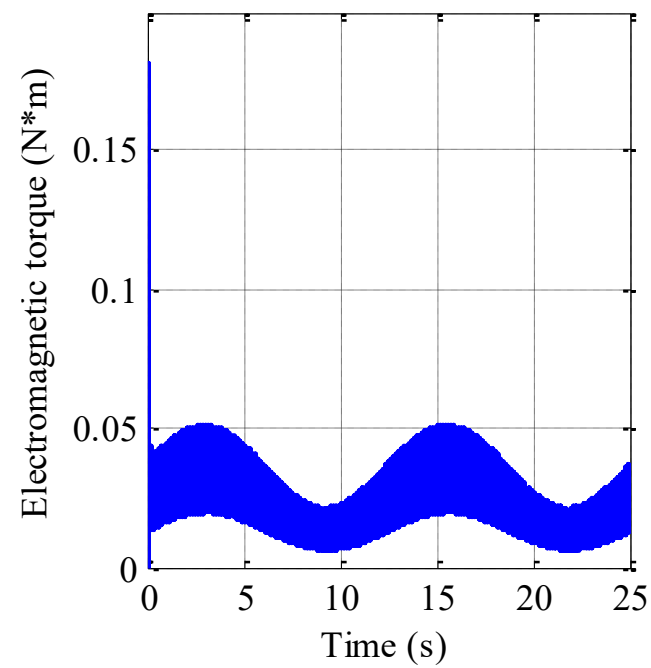

Fig. 16. Torque response to sinusoidal reference signal from 1000 to $3000 \mathrm{rpm}$ at $0.5 \mathrm{rad} / \mathrm{s}$.

From the Fig. 15 it can be seen how, as it is a tracking test, in this case of a sinusoidal signal, the control input tends to adopt the shape of the reference signal since there are no abrupt changes and the system shows to follow effectively the reference.

From the Fig. 16 it is observed how the motor torque acquires a sinusoidal shape like the control input, presenting a single peak at the beginning due to the sudden demand for speed that starts at 2000rpm.
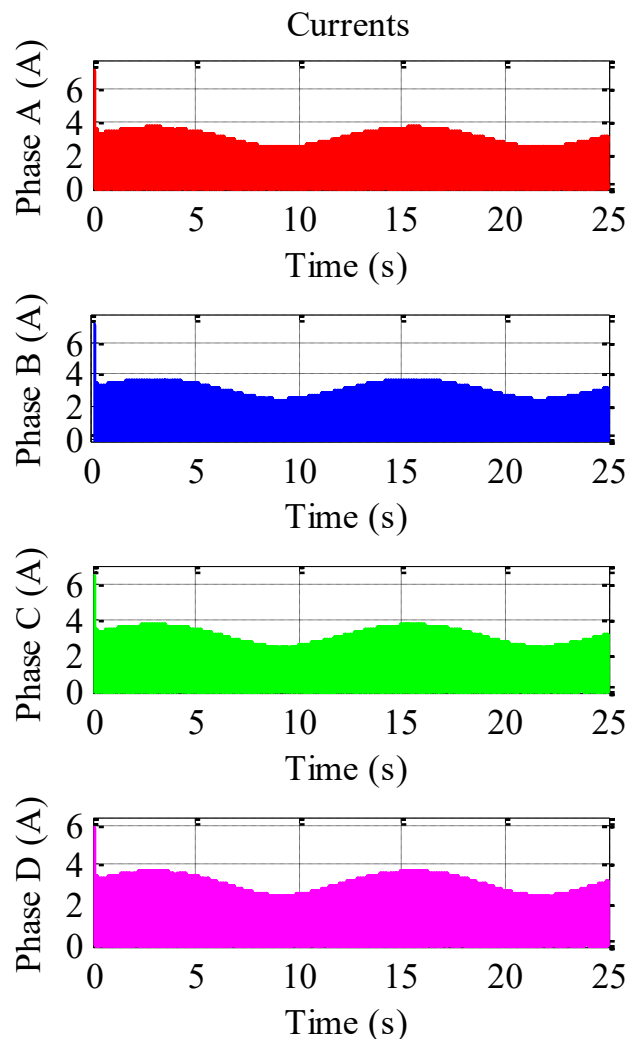

Fig. 17. Phase currents responses to sinusoidal to reference signal from 1000 to $3000 \mathrm{rpm}$ at $0.5 \mathrm{rad} / \mathrm{s}$.

Finally, from the Fig. 17, the current responses of each of the phases are observed, in them it is noted that the maximum value that the currents reach does not exceed $4 \mathrm{~A}$ and the average value is close to $2 \mathrm{~A}$.

For the following test, the frequency of the reference signal is increased to $1 \mathrm{rad} / \mathrm{s}$ to observe the behavior of the system with frequencies close to the bandwidth. The graphs obtained are shown in Figs. 18 to 21 .

In Fig. 18 The rotor speed response is shown, where it is observed how it fails to reach the peak values of the reference signal, obtaining maximum speeds of 2950rpm and minimum speeds of $1025 \mathrm{rpm}$ that correspond to an error value of $1.67 \%$ and $2.5 \%$, respectively. Furthermore, it is observed that there is a time lag of approximately 0.2 seconds. This speed response is expected because the frequency of the reference signal is $1 \mathrm{rad} / \mathrm{s}$ very close to the frequency of the bandwidth, for this reason, the gain of the system is reduced and an there is a time lag. 


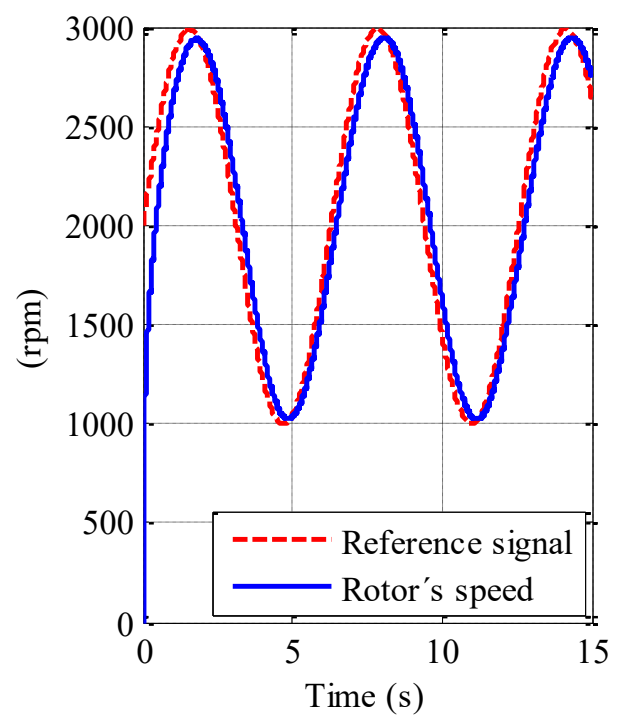

Fig. 18. Rotor's speed response to sinusoidal reference signal from 1000 to $3000 \mathrm{rpm}$ at $1 \mathrm{rad} / \mathrm{s}$.

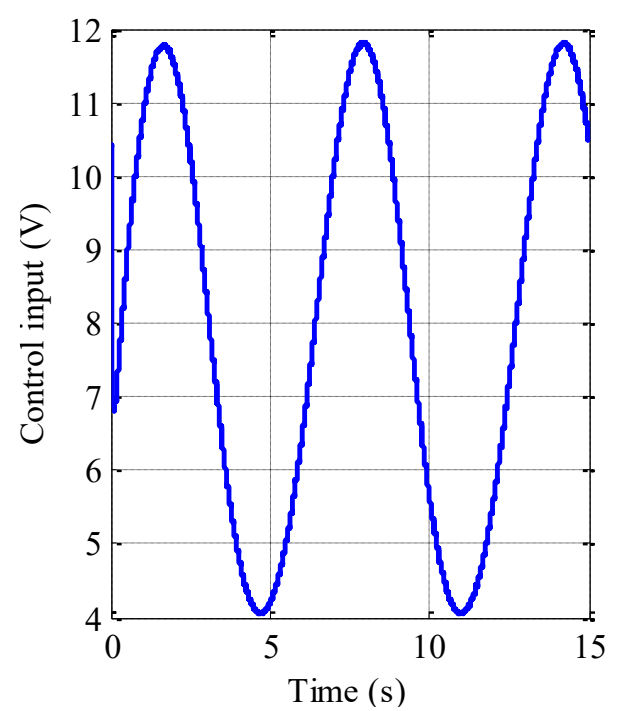

Fig. 19. Control input response to sinusoidal reference signal from 1000 to $3000 \mathrm{rpm}$ at $1 \mathrm{rad} / \mathrm{s}$.

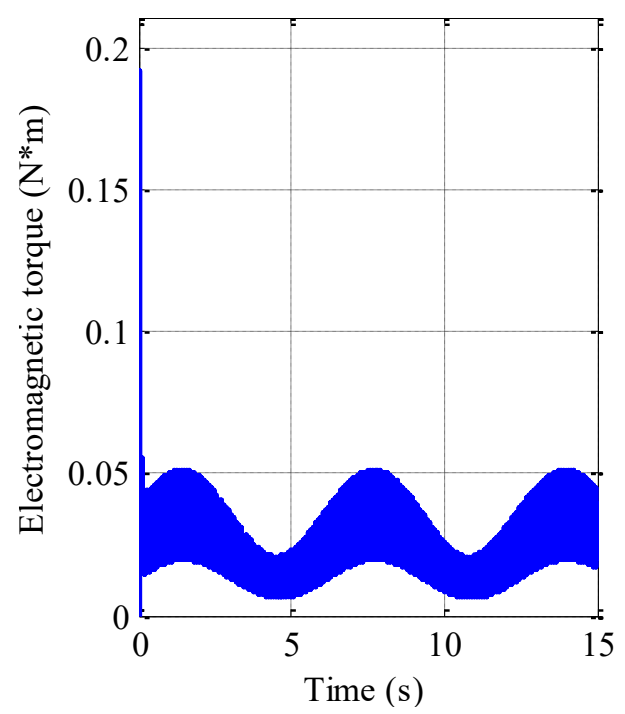

Fig. 20. Torque response to sinusoidal reference signal from 1000 to $3000 \mathrm{rpm}$ at $1 \mathrm{rad} / \mathrm{s}$.
On the other hand, in the case of the control input, torque and phase currents responses, the differences obtained with respect to the previous test are minimal. That is, the control input obtains peak values very similar to the previous test, while the torque only differs from the peak obtained at the beginning of the simulation, this is due to the fact that the reference signal is twice as fast as the previous signal. Finally, the current responses behave identical to that obtained from the previous test, obtaining an average consumption of $2 \mathrm{~A}$.
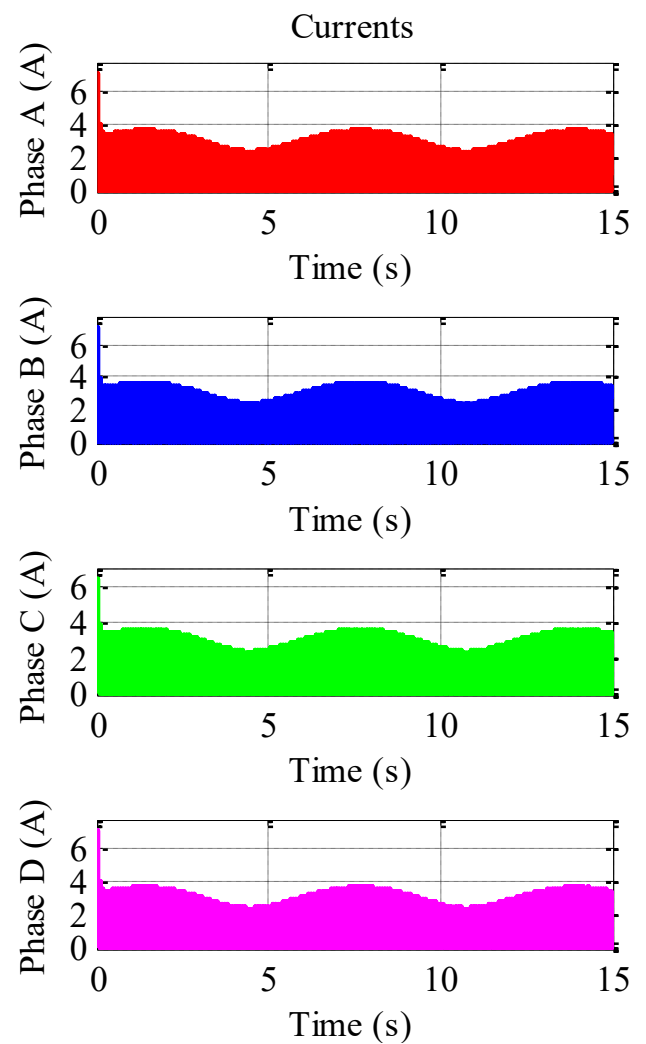

Fig. 21. Phase currents responses to sinusoidal to reference signal from 1000 to $3000 \mathrm{rpm}$ at $1 \mathrm{rad} / \mathrm{s}$.

As a final test, a reference signal is given that oscillates around $2000 \mathrm{rpm}$ with an amplitude of 500 $\mathrm{rpm}$ and a frequency of $0.5 \mathrm{rad} / \mathrm{s}$ for 30 seconds, subsequently repeating the above but around 2000 $\mathrm{rpm}$. With this reference signal it will be possible to observe the behavior of the controller in a more demanding follow-up test. The responses obtained are shown in Figs. 22 to 25.

In Fig. 22 it is observed how the rotor speed follows the reference signal in such a way that both signals are almost identical throughout the test, except in the instants in which there are considerable speed changes. In the case of the control input of Fig. 23, it is observed how it oscillates symmetrically, reaching voltage peaks of approximately $10 \mathrm{~V}$, in abrupt speed changes. The same happens in both the torque response and the current response. 


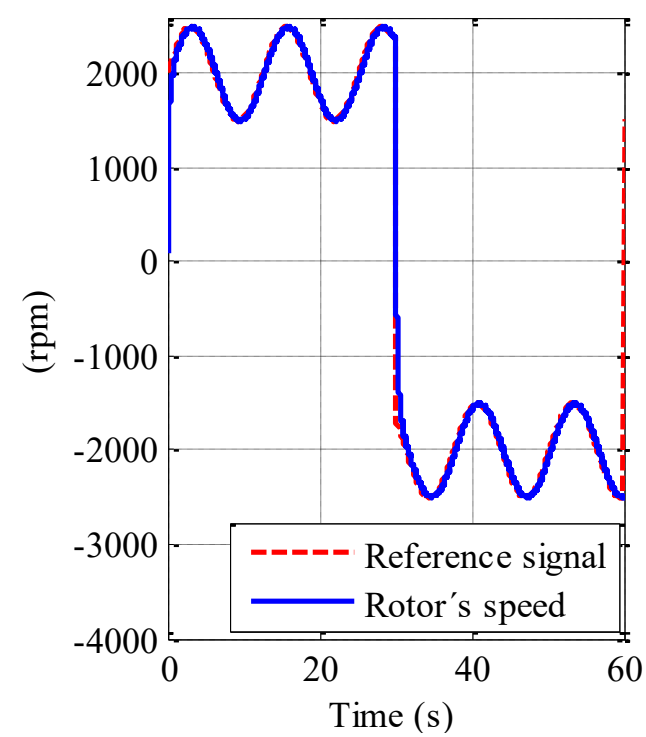

Fig. 22. Rotor's speed response to combined reference signal.

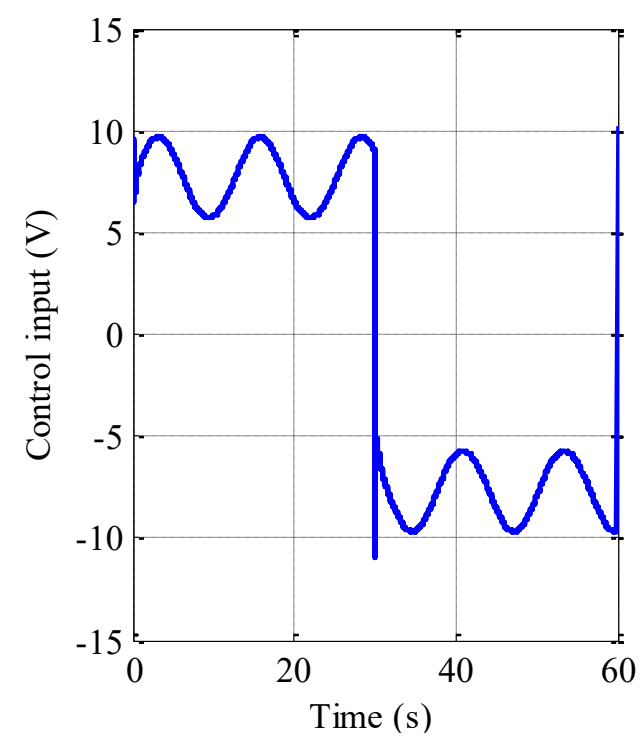

Fig. 23. Control input response to combined reference signal.

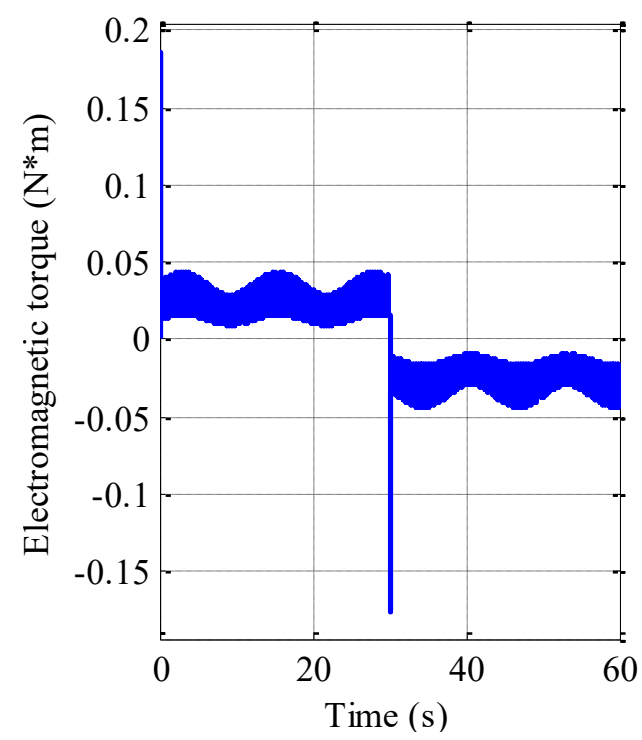

Fig. 24. Torque response to combined reference signal.
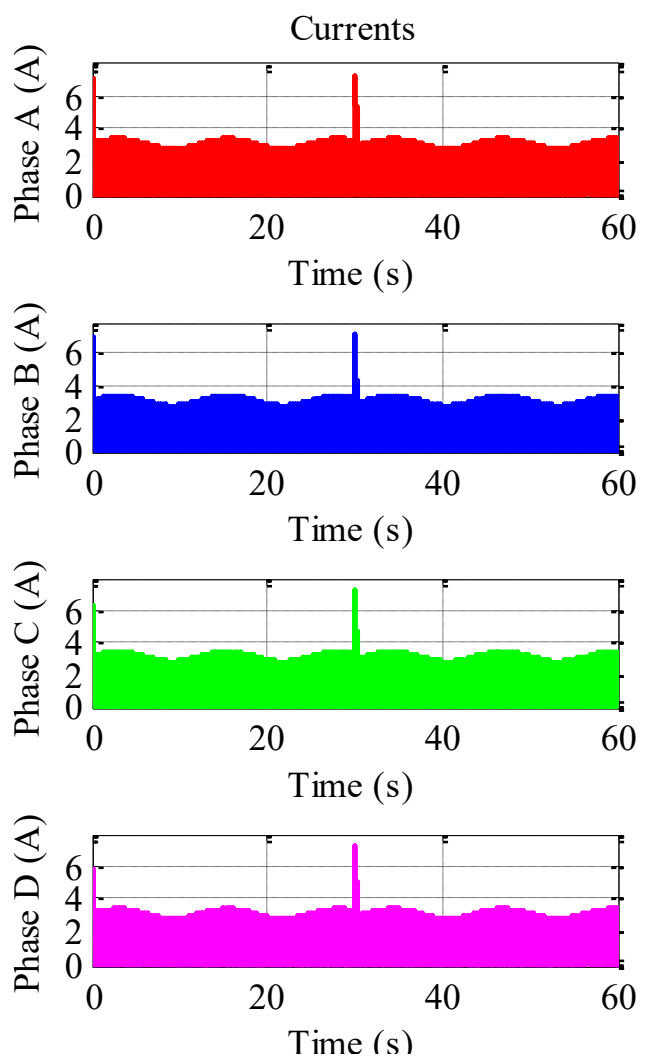

Fig. 25. Phase currents responses to combined reference signal.

\section{Conclusion}

In this document, a robust PI controller was proposed for the speed control of an SRM 8/6, designed from the linear model, since the great advantage that this model offers over others is the applicability of linear control techniques. The simulation considers an ideal inverter circuit and Coulomb plus viscous friction.

From the tests carried out, it was observed that the proposed controller proved to have a performance both in regulation and in tracking, in a wide operating range, thus proving that it is possible to design high performance and robust controllers for this type of motors from a linear model. Some of practical applications for this controller can be some of those mentioned in the introduction, such as washing machines, electric doors, vacuum cleaners, air conditioning, etc. The main limitation of the use of this controller is directly related to the region of operation and the error that can be admitted in the speed response, this is determined by the SRM application. Furthermore, when it is desired to operate the motor at low speeds the dead zone problem arises, causing the motor to respond adequately until the control input is large enough.

Some recommendations for future work are to apply the controller to a more complete SRM model, such as the nonlinear model with saturation of the 
material or a model using the finite element method, in this way more precise answers could be obtained that help to predict the results of applying this controller to a real motor. On the other hand, it is necessary to implement some control strategy that allows reducing undesirable oscillations in the rotor speed response. To reduce the effect of the dead zone it is recommended to implement a proportional controller with double integral effect (PII), since this controller has proven to be effective in other works

\section{References:}

[1] K. Kiyota, T. Kakishima, and A. Chiba, "Comparison of test result and design stage prediction of switched reluctance motor competitive with $60 \mathrm{kw}$ rare-earth pm motor," IEEE Transactions on Industrial Electronics, vol. 61, no. 10, pp. 5712-5721, 2014.

[2] T. J. E. Miller, Electronic control of switched reluctance machines. Elsevier, 2001.

[3] A. E. Fitzgerald, C. Kingsley, S. D. Umans, and B. James, Electric machinery. McGraw-Hill New York, 2003, vol. 5.

[4] R. Krishnan, Switched reluctance motor drives: modeling, simulation, analysis, design, and applications. CRC press, 2017.

[5] J.-W. Ahn and G. F. Lukman, "Switched reluctance motor: Research trends and overview," CES Transactions on Electrical Machines and Systems, vol. 2, no. 4, pp. 339347, 2018.

[6] J. Villegas and P. Vázquez, "Diseño de un sistema de control predictivo para el accionamiento de la máquina de reluctancia conmutada de un sistema de almacenamiento cinético para la mejora de la eficiencia en la edificación," Ph.D. dissertation, Universidad de Sevilla, Escuela Técnica Superior de Ingenieros, 2009.

[7] L. Liu, M. Zhao, X. Yuan, and Y. Ruan, "Direct instantaneous torque control system for switched reluctance motor in electric vehicles," The Journal of Engineering, vol. 2019, no. 16, pp. 1847-1852, 2019.

[8] S. Wang, Z. Hu, and X. Cui, "Research on novel direct instantaneous torque control strategy for switched reluctance motor," IEEE Access, vol. 8, pp. 66 910-66 916, 2020.

[9] M. Ma, Z. Wang, Q. Yang, S. Yang, and X. Zhang, "Vector control strategy of a t-type three-level converter driving a switched reluctance motor," Chinese Journal of Electrical Engineering, vol. 5, no. 4, pp. 15-21, 2019.
[10] K. Aiso and K. Akatsu, "High speed SRM using vector control for electric vehicle," CES Transactions on Electrical Machines and Systems, vol. 4, no. 1, pp. 61-68, 2020.

[11] H. Haq and H. I. Okumus, "Flc-dtc method for torque ripples minimization of $8 / 6$ switched reluctance motors drive," JAREE (Journal on Advanced Research in Electrical Engineering), vol. 4, no. 1, 2020.

[12] A. Uysal, S. Gokay, E. Soylu, T. Soylu, and S. Çaşka, "Fuzzy proportional-integral speed control of switched reluctance motor with matlab/simulink and programmable logic controller communication," Measurement and Control, vol. 52, no. 7-8, pp. 1137-1144, 2019.

[13] J. D. González-San Román, J. U. LiceagaCastro, I. I. Siller-Alcalá and E. CamperoLittlewood " Comparison of linear and nonlinear models of a switched reluctance motor $8 / 6, "$ Accepted for publication in 2020 25th International Conference on Circuits, Systems, Communications and Computers (CSCC).

[14] A. De la Guerra, "Observabilidad de motores de reluctancia conmutada," Master's thesis, Universidad Nacional Autónoma de México, Facultad de ingeniería, 2011.

[15] F. Khorrami, P. Krishnamurthy, and H. Melkote, Modeling and adaptive nonlinear control of electric motors. Springer Science \& Business Media, 2003.

[16] H. K. Khalil and J. W. Grizzle, Nonlinear systems. Prentice hall Upper Saddle River, NJ, 2002, vol. 3.

[17] K. Ogata, Ingeniería de control moderna. Pearson Educación, 2010, vol. 5.

[18] B. Saidi, M. Amairi, S. Najar, and M. Aoun, "Bode shaping-based design methods of a fractional order pid controller for uncertain systems," Nonlinear Dynamics, vol. 80, no. 4, pp. 1817-1838, 2015.

[19] N. Zhuo-Yun, Z. Yi-Min, W. Qing-Guo, L. RuiJuan, and X. Lei-Jun, "Fractional-order pid controller design for time-delay systems based on modified bode's ideal transfer function," IEEE Access, vol. 8, pp. 103 500-103 510, 2020.

[20] C. A. Pérez-Gómez, J. U. Liceaga-Castro, and I. I. Siller-Alcalá, "Comparative study between classical controllers and inverse dead zone control for position control of a permanent magnet dc motor with dead zone," in TRANSACTIONS on POWER SYSTEMS, vol. 15. WSEAS, 2020. 


\section{Contribution of individual authors to the creation of a scientific article}

Jesús D. González-San Román programmed the models, carried out the simulations and contributed to the theoretical analysis and design of the controller.

Jesús U. Liceaga-Castro and Irma I. Siller-Alcalá contributed to the theoretical analysis and design of the controller.

Eduardo Campero-Littlewood carried out the electrical motor's analysis.

\section{Sources of funding for research presented in a scientific article or scientific article itself}

The project was funded by the UAM-Azc and by CONACYT scholarship grant to Jesús D. GonzálezSan Román

\section{Creative Commons Attribution \\ License 4.0 (Attribution 4.0 International , CC BY 4.0)}

This article is published under the terms of the Creative Commons Attribution License 4.0

https://creativecommons.org/licenses/by/4.0/deed .en_US 